\title{
Physical properties of high pressure reactively sputtered hafnium oxide
}

\author{
M. Toledano-Luque a,*, F.L. Martínez ${ }^{\text {b }}$, E. San Andrés a , A. del Prado ${ }^{a}$, I. Mártil ${ }^{a}$, \\ G. González-Díaz ${ }^{\mathrm{a}}$, W. Bohne ${ }^{\mathrm{c}}$, J. Röhrich ${ }^{\mathrm{c}}$, E. Strub ${ }^{\mathrm{c}}$ \\ ${ }^{a}$ Departamento de Física Aplicada III, Fac. Ciencias Físicas, Universidad Complutense de Madrid, Ciudad Universitaria, E-28040 Madrid, Spain \\ ${ }^{\mathrm{b}}$ Departamento de Electrónica y Tecnología de Computadoras, Universidad Politécnica de Cartagena, E-30202 Cartagena, Spain \\ ${ }^{\mathrm{c}}$ Hahn-Meitner-Institut Berlin, Abteilung SF-4, D-14109 Berlin, Germany
}

\section{Keywords:}

Hafnium oxide

Sputtering

TEM

XRD

FTIR

HI-ERDA

\begin{abstract}
A B S T R A C T
Hafnium oxide films were deposited on silicon by High Pressure Reactive Sputtering (HPRS) at pressures between 0.8 and 1.6 mbar. Growth, composition and morphology were investigated using Transmission Electron Microscopy (TEM), Heavy Ion Elastic Recoil Detection Analysis (HI-ERDA), Fourier Transform Infrared spectroscopy (FTIR) and X-Ray Diffraction (XRD). The growth rate was found to decrease exponentially with deposition pressure. The films showed a monoclinic polycrystalline structure, with higher grain size for intermediate pressures. All the films were slightly oxygen rich with respect to stoichiometric $\mathrm{HfO}_{2}$, which is attributed to the oxygen plasma. Additionally, it was observed the formation of an interfacial silicon oxide layer, with a minimum thickness for deposition pressures around 1.2 mbar. These results are explained by the oxidation action of the oxygen plasma and the diffusion of oxygen through the grain boundaries of the $\mathrm{HfO}_{2}$ film.
\end{abstract}

(c) 2008 Elsevier Ltd. All rights reserved.

\section{Introduction}

Thin films of high-k materials, especially hafnium oxide $\left(\mathrm{HfO}_{2}\right)$, have been extensively studied during the last years due to being considered suitable candidates for replacing the gate dielectrics in field effect transistors and dynamic random access memories [1]. The scaling down of complementary metal-oxide-semiconductor (CMOS) technology requires a silicon oxide $\left(\mathrm{SiO}_{2}\right)$ thickness below $1.1 \mathrm{~nm}$ with tunneling leakage current lower than $0.1 \mathrm{~A} / \mathrm{cm}^{2}[1]$. A thin film with higher permittivity than $\mathrm{SiO}_{2}$ can be thicker than a $\mathrm{SiO}_{2}$ thin film, keeping the same capacitance and avoiding the tunneling current. Silicon oxynitride [2-4] and silicon nitride [5-8] were researched and implemented as a transitory solution to reduce the leakage currents. However, a more aggressive downscaling of the transistor dimensions requires materials with higher dielectric constant than the silicon oxynitride. One of the most promising candidates due to its high dielectric constant value, thermal stability on $\mathrm{Si}$, and large conduction band offset with respect to $\mathrm{Si}$ is hafnium oxide [1].

Nowadays, most of the studies about $\mathrm{HfO}_{2}$ are focused on its dielectric properties. However, $\mathrm{HfO}_{2}$ is also an interesting material for a broad range of applications: $\mathrm{HfO}_{2}$ thin films are used as optical coatings for CCDs [9], as well as antireflective multilayer coatings for night vision devices [10], due to its large band gap and refractive

\footnotetext{
* Corresponding author. Fax: +34 913945196.

E-mail address: mtluque@fis.ucm.es (M. Toledano-Luque).
}

index. Moreover, $\mathrm{HfO}_{2}$ shows a high chemical inertness, thus being an interesting protective coating for applications in contact with harsh environments [11]. $\mathrm{HfO}_{2}$ applications also extend to the $\mathrm{pH}$, $\mathrm{Na}^{+}, \mathrm{K}^{+}$and, $\mathrm{H}^{+}$chemical sensors [12] and to chip temperature detection [13]. Therefore, a thorough study of its physical properties is constructive.

In this work, the growth and physical properties (composition, crystallinity, surface and interface morphology) of $\mathrm{HfO}_{2}$ thin films by high-pressure reactive sputtering (HPRS) [14] is studied as a function of the deposition pressure. This non-conventional deposition method works at chamber pressures about $1 \mathrm{mbar}$, two or three orders of magnitude higher than in conventional sputtering systems. This technique has been used to grow high- $\mathrm{T}_{\mathrm{C}}$ superconductors [15] and, recently, has been successfully used to deposit titanium oxide [16]. This deposition method reduces the damage to the interface and the film during the growth because the mean free path of the high-energy species emitted by the target is significantly shorter, thus preventing the impact of energetic species on the substrate and on the growing film.

\section{Experimental details}

The details of the HPRS system used to grow the $\mathrm{HfO}_{2}$ films are given elsewhere [6]. A commercial $\mathrm{HfO}_{2}$ target with nominal purity of $99.95 \%$ and a diameter of $4.5 \mathrm{~cm}$ was used. The radio frequency power was kept at $60 \mathrm{~W} . \mathrm{O}_{2}$ was used as reactive gas. It is emphasized that the only elements purposefully introduced in the process are those composing the deposited film: Hf and $\mathrm{O}$. The 
depositions were performed for $3 \mathrm{~h}$ at a temperature of $200^{\circ} \mathrm{C}$. The base pressure was about $2 \times 10^{-5} \mathrm{mbar}$. The pressure range of study was from 0.8 mbar to 1.6 mbar.

Several techniques were combined to study the dependency of the growth and physical properties of the films with deposition pressure. The bonding structure was studied by Fourier Transform Infrared Spectroscopy (FTIR) in the $100-4000 \mathrm{~cm}^{-1}$ range using a Nicolet Magna-IR 750 series II spectrometer working in the transmission mode at normal incidence. The spectrum of the insulator was obtained by subtracting the spectrum of a bare Si sample from the total signal (Si-substrate + deposited film). The stoichiometry of the films was measured by Heavy Ion Elastic Recoil Detection Analysis (HI-ERDA) using $350 \mathrm{MeV}$ Au ions. The different species were identified using the time-of-flight technique $[17,18]$. Ion fluence was in the order of $10^{12}$ atoms $/ \mathrm{cm}^{2}$, which is low enough to minimize preferential effusion effects of light atoms, taking place at higher ion fluence [19]. This technique provides the absolute atomic concentrations of every species present in the film, without need for calibration standards. The crystallinity of the films was studied by X-Ray Diffraction (XRD) using a Philips XPERT diffractometer in $\theta-2 \theta$ configuration with $\mathrm{Cu} \mathrm{K} \alpha$ radiation. The $\mathrm{HfO}_{2}$ peak near $2 \theta=28.2^{\circ}$ was used to estimate the grain size by means of Scherrer equation [20]. Finally, the film and interface morphology and film thickness were investigated by Transmission Electron Microscopy (TEM) using a JEOL JEM-2000FX microscope operated at $200 \mathrm{kV}$.

The silicon substrate for the $\mathrm{HfO}_{2}$ growth was selected according to the characterization technique. For the infrared spectroscopy, the samples were deposited on double side polished p-Si (111) wafers with high resistivity $(80 \Omega \mathrm{cm})$. The samples for the other techniques were prepared on single side polished n-Si (100) wafers with a resistivity of $4.6-5.0 \Omega \mathrm{cm}$. The wafers were cut in $1 \times 1 \mathrm{~cm}^{2}$ pieces and subjected to a standard RCA cleaning method [21]. Just before introduction into the chamber, the native oxide was removed by immersion in diluted HF (50:1) for $30 \mathrm{~s}$.

\section{Results and discussion}

Fig. 1 shows the FTIR spectra of $\mathrm{HfO}_{2}$ films deposited at different deposition pressures. Note that each spectrum is displayed in two frequency regions that partly overlap corresponding to the detectors

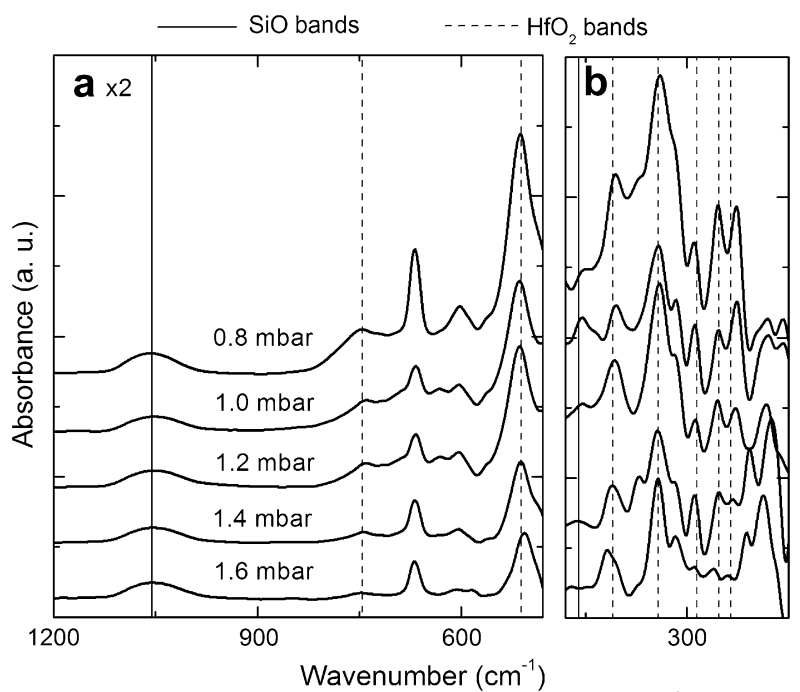

Fig. 1. FTIR spectra in two frequency regions: (a) $1200-350 \mathrm{~cm}^{-1}$ and (b) $600-150$ $\mathrm{cm}^{-1}$ of samples deposited at different pressures. Main absorption bands corresponding to monoclinic $\mathrm{HfO}_{2}$ are also shown.
Table 1

Composition results obtained by ERDA of samples deposited at different deposition pressures. The uncertainty of the $[\mathrm{O}] /[\mathrm{Hf}]$ ratio is about $5 \%$

\begin{tabular}{lrrrrrrr}
\hline p (mbar) & 0.8 & \multicolumn{1}{c}{0.9} & 1.0 & 1.1 & 1.2 & 1.4 & 1.6 \\
Hf (\%at) & 30.73 & 30.10 & 30.36 & 29.40 & 28.50 & 29.40 & 30.59 \\
O (\%at) & 65.00 & 62.47 & 61.44 & 63.56 & 62.57 & 63.69 & 62.30 \\
H (\%at) & 3.18 & 5.50 & 5.10 & 4.00 & 5.30 & 6.00 & 6.00 \\
B, C, N, F, Zr (at.\%) & 1.09 & 1.93 & 3.10 & 3.04 & 3.63 & 0.91 & 1.11 \\
[O]/[Hf] & 2.12 & 2.07 & 2.02 & 2.16 & 2.19 & 2.17 & 2.04 \\
\hline
\end{tabular}

used in the measurement. The IR spectra were measured between 150 and $4000 \mathrm{~cm}^{-1}$, but the only significant spectral features were found in the $150-1350 \mathrm{~cm}^{-1}$ region, which is shown in Fig. 1.

The absorption bands assigned to $\mathrm{HfO}_{2}$ are consistent with the ones given in the literature for monoclinic $\mathrm{HfO}_{2}$ [22]. The main peaks are situated at 512,410 , and $343 \mathrm{~cm}^{-1}$. The band height and area of these peaks decreased with increasing deposition pressure. It is known that the band area is proportional to the concentration of bonds associated to that band. Therefore, these results could indicate that the $\mathrm{HfO}_{2}$ thickness decreases when the deposition pressure increases.

Additionally, a band located at $1056 \mathrm{~cm}^{-1}$ is observed in all samples. This wave number is characteristic of the $\mathrm{Si}-\mathrm{O}-\mathrm{Si}$ stretching mode in strained $\mathrm{SiO}_{2}$ [13]. We attribute this band to the formation of an interfacial $\mathrm{SiO}_{2}$ layer between the $\mathrm{HfO}_{2}$ film and the Si-substrate during the deposition. The presence of silicon suboxides near the $\mathrm{Si} / \mathrm{SiO}_{2}$ interface [23] and/or the fact that $\mathrm{Hf}-\mathrm{O}$ bonds are longer than the $\mathrm{Si}-\mathrm{O}$ bonds [24] may be responsible for the strain in this layer. A minimum in the area of this band was observed for the films deposited at 1.2 mbar, suggesting a minimum in the thickness of the $\mathrm{SiO}_{2}$ interfacial layer.

Table 1 summarizes the atomic concentrations of the different elements measured by HI-ERDA. In addition to $\mathrm{Hf}$ and $\mathrm{O}$, significant amounts of $\mathrm{H}$ (up to 6 at.\%) were observed. Hydrogen and nitrogen may have been incorporated into the film during the deposition due to the residual gas in the chamber or in the time between deposition and HI-ERDA characterization. Moreover, $\mathrm{H}$ may come from $\mathrm{Si}-\mathrm{H}$ bonds present on the surface of the HF dipped Si-substrates. Zirconium comes from the $\mathrm{HfO}_{2}$ target itself because $\mathrm{Zr}$ is a usual impurity in the hafnium. $\mathrm{B}$ is likely to come from the $\mathrm{HfO}_{2}$ target itself.

The measured oxygen to hafnium ratio ( $x$ in the following) is also shown in Table 1. All samples are slightly oxygen rich, with

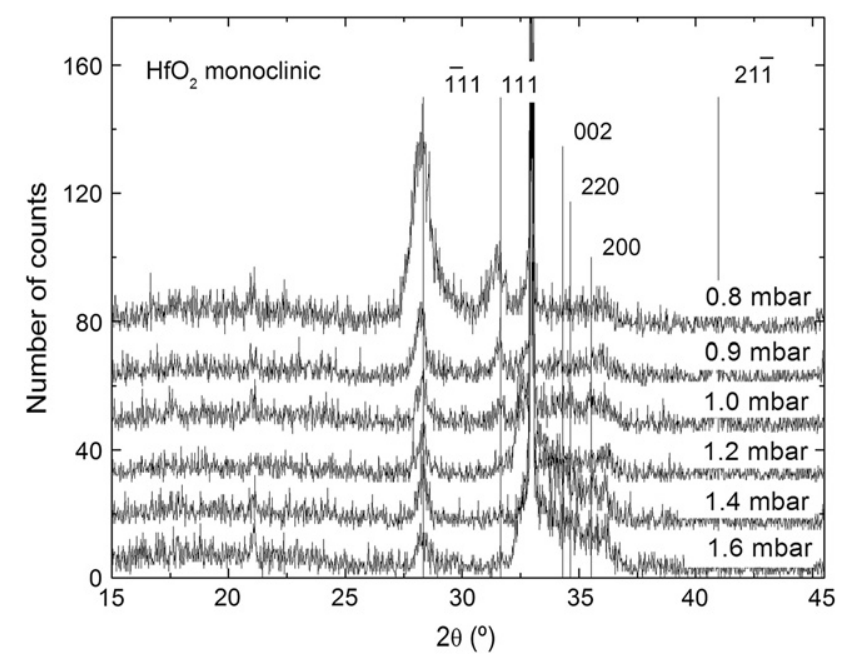

Fig. 2. XRD diagrams from samples deposited at different pressures. Main peaks are labeled according to the pattern of monoclinic $\mathrm{HfO}_{2}$. 




Fig. 3. Cross-sectional TEM images of $\mathrm{HfO}_{2}$ deposited at different pressures.

measured $x$ values between 2.02 and 2.19. This deviation from the stoichiometric value is attributed to the incorporation of oxygen from the oxygen plasma during the deposition process.

Fig. 2 shows the XRD spectra of the $\mathrm{HfO}_{2}$ films deposited at different pressures shown in Fig. 3. The XRD measurements demonstrate that the $\mathrm{HfO}_{2}$ films are polycrystalline and the peak positions confirm a monoclinic phase [25] in agreement with the FTIR results. The peak intensity of the $(\overline{111})$ monoclinic $\mathrm{HfO}_{2}$ feature increases with decreasing deposition pressure. The average grain size was estimated according to Scherrer equation from the FWHM of the (111) reflection, obtained from a fit of the spectrum to a Gaussian line shape. The sample deposited at 0.8 mbar presents the smallest grain size $(\sim 8 \mathrm{~nm})$, whereas the samples deposited between 0.9 and 1.4 mbar have a roughly constant grain size $(\sim 20$ $\mathrm{nm})$. Finally, at $1.6 \mathrm{mbar}$ the grain size decreases with respect to middle deposition pressures $(\sim 16 \mathrm{~nm})$.

Fig. 3 shows the cross-sectional TEM images of $\mathrm{HfO}_{2}$ films deposited at different pressures. A polycrystalline layer (dark film) is observed on top of an amorphous thinner film (bright film). The Sisubstrate is found under this amorphous layer. The electron diffraction patterns (not shown) of the dark films are identified as polycrystalline monoclinic phase of $\mathrm{HfO}_{2}$ in agreement with XRD and FTIR measurements. The TEM images also show that the grain morphology is columnar. The amorphous film is identified as $\mathrm{SiO}_{2}$, in agreement with the FTIR results.

From the TEM observations, the actual thickness of the $\mathrm{HfO}_{2}$ films and the interfacial $\mathrm{SiO}_{2}$ layers (Fig. 3) were determined. Fig. 4a shows that the thickness of the $\mathrm{HfO}_{2}$ films decreases with increasing deposition pressure, as previously suggested by the FTIR results. The relationship between the thickness and the pressure can be fitted to Eq. (1).

$t_{\mathrm{HfO}_{2}}(\mathrm{~nm})=101 \cdot p(\text { mbar })^{-1.75}$

Znamenskii et al. [26] found a similar dependency of the sputtering rate on the pressure for high-pressure magnetron sputtering: $j_{s} \approx p^{-2}$, and proposed a diffusional model of the transport of the thermalized atoms. This model is also applicable to our HPRS system.

Fig. 4b shows the thickness of the interfacial $\mathrm{SiO}_{2}$ layer as a function of deposition pressure. A minimum is observed for pressures around 1.2 mbar. The growth of the $\mathrm{SiO}_{2}$ interface is mainly due to two different processes. First, the $\mathrm{SiO}_{2}$ layer starts growing during the initial stages of the sputtering process as a result of the oxidation of the silicon surface. The energy to dissociate oxygen molecule is only $5.2 \mathrm{eV}$, which is close to the electron energy in a glow discharge [27]. The chemically active oxygen radicals may react with the silicon substrate to form the $\mathrm{SiO}_{2}$ interface layer. On the other hand, the dependence of the $\mathrm{SiO}_{2}$ thickness on the deposition pressure can be explained by grain boundary diffusion of oxygen through the $\mathrm{HfO}_{2}$. In polycrystalline materials, the grain boundary diffusion is proportional to the grain boundary area (or the inverse of the grain size) [28]. Therefore, the $\mathrm{SiO}_{2}$ thickness is expected to be thinner when the maximum grain size is found, which is the observed trend in our samples.

The uncontrolled formation of $\mathrm{SiO}_{2}$ interfaces is the main problem that the high-k materials deposited by sputtering present to achieve the electrical capacitance demanded by the industry. We have started to work on a modification of our system in order to

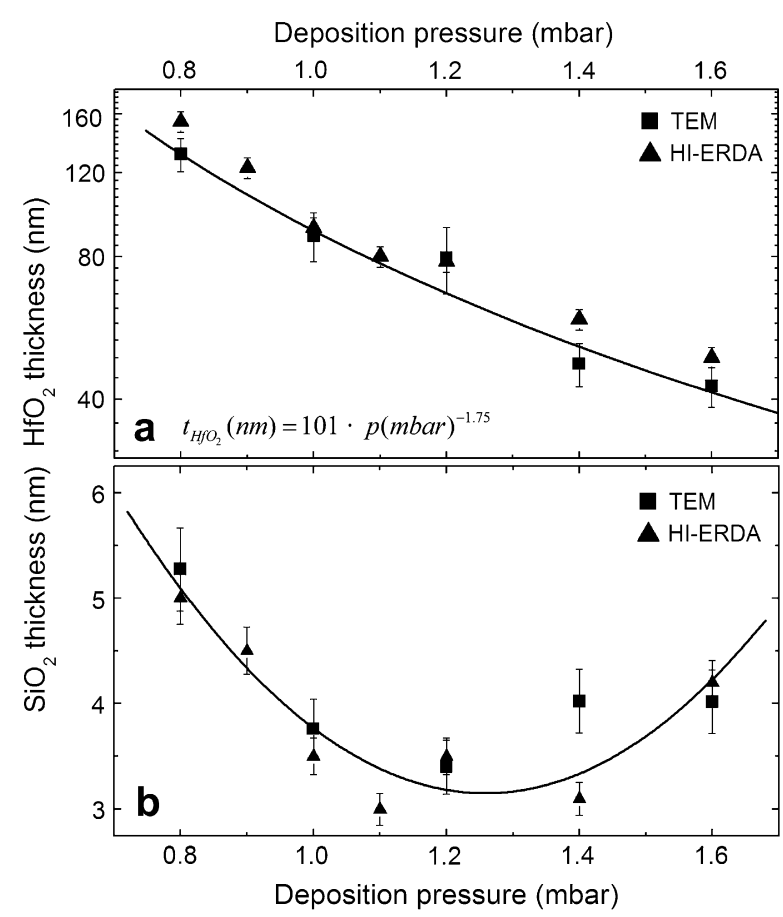

Fig. 4. Thickness of the $\mathrm{HfO}_{2}$ films (a), and $\mathrm{SiO}_{2}$ interfacial layers (b) as a function of the deposition pressure. Values were obtained by HI-ERDA areal density and by crosssections TEM. 
perform the growth process with an argon plasma to reduce the $\mathrm{SiO}_{2}$ interfacial thickness, and therefore to increase the electrical capacitance of the $\mathrm{HfO}_{2} / \mathrm{SiO}_{2}$ structure.

\section{Conclusion}

The physical properties of $\mathrm{HfO}_{2}$ deposited by HPRS at different pressures and growth kinetics have been studied by means of the combination of several techniques. From the HI-ERDA measurements, we observed a slightly oxygen rich stoichiometry, which is attributed to the incorporation of plasma oxygen. The main impurity found was hydrogen, although traces from other light atoms such as B, C, N and F were also detected. Several techniques have shown that the deposited $\mathrm{HfO}_{2}$ films were polycrystalline, and that the crystal structure was monoclinic. The influence of the deposition pressure on the grain size and on the deposition rate of the $\mathrm{HfO}_{2}$ films and $\mathrm{SiO}_{2}$ interfaces was studied. The $\mathrm{HfO}_{2}$ thickness decreased exponentially when the deposition pressure increased, which is attributed to the less efficient process of transport of sputtered species through the plasma towards the substrate. The $\mathrm{SiO}_{2}$ thickness showed an initial decrease as function of the pressure up to $1.2 \mathrm{mbar}$, this trend was inverted at higher pressures. The minimum $\mathrm{SiO}_{2}$ thickness was reached when the size of the crystallites was maximum. Based on these results, and apart from an initial growth due to the oxidation of the silicon surface, we established that the growth of the interface was due to the grain boundary diffusion of oxygen through the $\mathrm{HfO}_{2}$ film.

\section{Acknowledgements}

The authors acknowledge C.A.I de Implantación Iónica (U.C.M.), C.A.I de Espectroscopía y Espectrometría and C.A.I. de Microscopía y Citometría for technical support. This work was made possible thanks to a FPU grant of the Spanish M.E.C. This work was also supported by the Spanish M.C.Y.T., under the contract TEC 2004-1237/MIC.

\section{References}

[1] Robertson J. Rep Prog Phys 2006;69:327.

[2] del Prado A, San Andrés E, Mártil I, González-Díaz G, Bravo D, López FJ, et al. J Appl Phys 2003;94:1019.

[3] del Prado A, San Andrés E, Mártil I, González-Díaz G, Bravo D, López FJ, et al. J Appl Phys 2003;93:8930.

[4] del Prado A, San Andrés E, Martínez FL, Mártil I, González-Díaz G, Bohne W, et al. Vacuum 2002;67:507.

[5] Martínez FL, del Prado A, Mártil I, González-Díaz G, Bohne W, Fuhs W, et al Phys Rev B 2001:63:245320.

[6] Martínez FL, Ruiz-Merino R, del Prado A, San Andrés E, Mártil I, GonzálezDíaz G, et al. Thin Solid Films 2004;459:203.

[7] Mártil I, del Prado A, San Andrés E, González-Díaz G, Martínez FL. J Appl Phys 2003;94:2642.

[8] San Andrés E, del Prado A, Mártil I, González-Díaz G, Martínez FL. J Vac Sci Technol 2003;21:1306.

[9] Lesser M. Opt Eng 1987;26:911.

[10] Fadel M, Azim OA, Omer OA, Basily RR. Appl Phys 1998;A 66:335.

[11] Grüger H, Kunath Ch, Kurth E, Sorge S, Pufe W, Pechstein T. Thin Solid Films 2004;447-448:509.

[12] Moldovan C, Iosub R, Modreanu M, Ulieru D, Firtat B, and Ion M, International Semiconductor Conference 2006.

[13] Wang T, Chang C, Hwu JG. IEEE Sens J 2006;6:1468.

[14] Poppe U, Klein N, Dháne U, Solner H, Jia CL, Kabius B, et al. J Appl Phys 1992; 71:5572.

[15] Navacerrada MA, Lucía ML, Sánchez-Quesada F. Phys Rev B 2000;61: 6422.

[16] San Andrés E, Toledano-Luque M, del Prado A, Navacerrada MA, Mártil I, González-Díaz G, et al. J Vac Sci Technol 2005;A 23:1253.

[17] Bohne W, Röhrich J, Röschert G. Nucl Instr Meth B 1998;136-138:633.

18] Bohne W, Hessler S, Röschert G. Nucl Instr Meth B 1996;113:78.

[19] Bohne W, Fuhs W, Röhrich J, Selle B, González-Díaz G, Mártil I, et al. Surf Interface Anal 2000;30:534.

[20] Cullity BD. Elements of x-ray diffraction. 2nd ed. Reading, MA: AddisonWesley; 1978.

[21] Kern W. RCA Rev 1970;31:187.

[22] Neumayer DA, Cartier E. J Appl Phys 2001;90:1801.

[23] Fitch JT, Kim SS, Lucovsky G. J Vac Sci Technol 1990;A 8:1871.

[24] Kawamoto A, Jameson J, Griffin P, Cho K, Dutton R. IEEE Electron Device Lett $2001 ; 22: 14$.

[25] Hann RE, Suitch PR, Pentecost JL. J Amer Ceram Soc 1985;68:285.

[26] Znamenski AG, Marchenko VA. Tech Phys 1998;43:766.

[27] Chapman B. Glow discharge processes. New York: Wiley; 1980

[28] Kingery WD, Bowen HK, Uhlmann DR. Introduction to ceramics. 2nd ed. John Wiley \& Sons; 1976. 